\title{
More Editorial Board Members and Kudos for the 2009 Practice-Based Research Network Poster Award
}

In an ongoing effort to introduce our readers to the distinguished members of the editorial board that advises the Fournal of the American Board of Family Medicine, in this issue we highlight Drs. Fenton, Figueroa, and Jimbo.

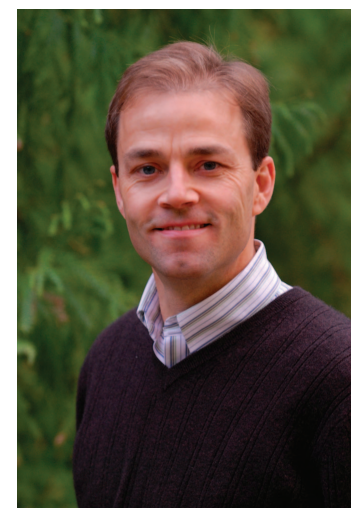

Dr. Joshua Fenton, MD, MPH

Dr. Joshua Fenton, MD, MPH, is a graduate of the University of California, San Francisco, and completed residency at San Francisco General Hospital. Subsequently he was a family physician on the Navajo Indian Reservation at Crownpoint, New Mexico, and a Robert Wood Johnson Clinical Scholar at the University of Washington, where he received an MPH in health services. Dr. Fenton is currently Assistant Professor of Family and Community Medicine at the University of California, Davis. An American Cancer Society Mentored Research Scholar, Dr. Fenton conducts research examining the dissemination and accuracy of breast and colorectal cancer screening tests.

Dr. Edgar Figueroa, MD, MPH, is currently Assistant Professor of Family Medicine in Medicine and Director of Student Health at Weill Cornell Medical College in New York City. A life-long

Conflict of interest: The authors are editors and staff of the 7ABFM.

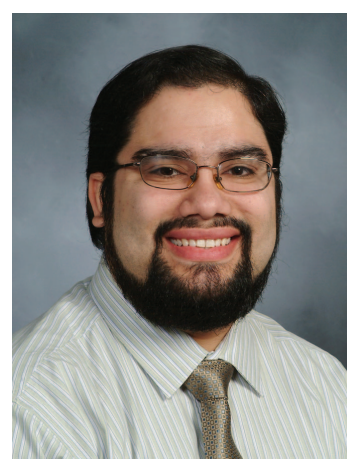

\section{Dr. Edgar Figueroa, MD, MPH}

New Yorker, he earned his medical degree from Weill Cornell Medical College and completed his residency at the Family Medicine Residency Program at New York Presbyterian Hospital—Columbia University Medical Center. He subsequently completed a faculty development fellowship and earned his MPH from Columbia University. His academic interests include web-based education, narrative medicine, health promotion in urban underserved populations, and understanding issues of diversity in academic medicine.

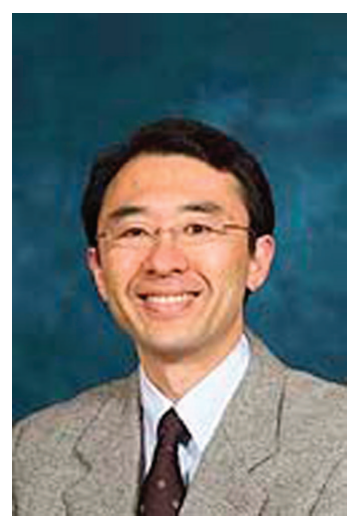

Dr. Masahito Jimbo, MD, PhD, MPH

Dr. Masahito Jimbo, $\mathbf{M D}, \mathbf{P h D}, \mathbf{M P H}$, is an associate professor of the Departments of Family 
Medicine and Urology at the University of Michigan. He obtained his medical and doctorate degrees from Keio University School of Medicine in Japan, and after completing an internal medicine residency at the same institution he completed his residency in family medicine at the Thomas Jefferson University in Philadelphia. He obtained a Master's in Public Health from the University of North Carolina at Chapel Hill while serving as a medical director in rural North Carolina. Dr. Jimbo practices a wide range of clinical medicine, including primary care for the Japanese population in southeastern Michigan, medical consultation for patients with urological problems, and hospital medicine. He is heavily involved in teaching the University of Michigan Family Medicine residents in hospital medicine and is a member of the Society of Teachers of Family Medicine Group on Hospital Medicine and Procedural Training. In addition, he teaches and lectures extensively in Japan, where he is a visiting professor at several institutions, including Okayama University and St. Marianna University. The main focus of Dr. Jimbo's research is patient-physician communication and cultural factors in cancer screening and prevention. He has published in national family medicine and cancer journals and is currently a coinvestigator in the federally funded Center of Excellence in Cancer Communications Research at the University of Michigan. He also educates the Japanese community about health and prevention through a monthly newspaper column, a bimonthly newsletter, and a monthly podcast.

\section{Congratulations to Dr. Ely!}

We also would like to take this opportunity to congratulate editorial board member, Dr. John W. Ely, MD, MSPH, who won the Practice-Based Research Network Poster Award at the 2009 Agency for Health care Research and Quality National Practice-Based Research Network Research Conference for his poster entitled "Primary Care Perceptions Regarding Community-Acquired Methicillin-Resistant Staphylococcus aureus Infections." Dr. Ely was previously featured in the September/ October 2009 issue of our Editorial Office News and Notes section. ${ }^{1}$

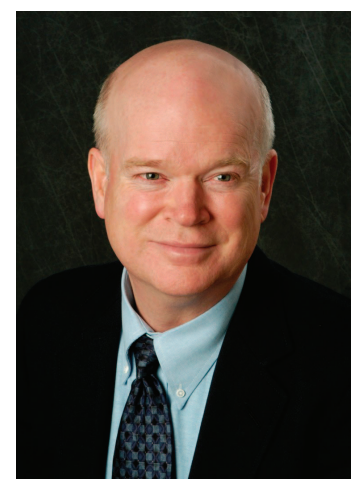

John W. Ely, MD, MSPH

\section{0th Anniversary Supplement}

Be sure to see the fournal of American Board of Family Medicine supplement from the American Board of Family Medicine's symposium celebrating its 40th Anniversary (Fournal of American Board of Family Medicine, March 2010, volume 23). In 1969, the American Board of Family Practice (now the American Board of Family Medicine) was approved and recognized as the 20th medical specialty in the United States by the American Board of Medical Specialties. As usual, family medicine was in the forefront of innovation as it became the first medical specialty board to issue time-limited certificates and to mandate recertification every 7 years. A number of interesting articles in this special issue discuss the past, present, and future of training and certification in our specialty.

\section{Looking Ahead}

Please look for a special report in the May/June 2010 issue about the top 20 Fournal of American Board of Family Medicine articles and online readership for 2009. The July/August 2010 issue will be dedicated to practice-based research networks (PBRNs).

Phillip Lupo, MLIS

Anne Victoria Neale, PhD, MPH

Marjorie A. Bowman, MD, MPA

\section{Reference}

1. Lupo P, Neale AV, Bowman MA. Introduction of more editorial board members and new guest commentary feature. J Am Board Fam Med 2009;22: $468-70$. 